\title{
Rechtsangleichung in der EU im Bereich der direkten Steuern
}

\author{
Analyse der Handlungsformen unter besonderer Berücksichtigung des Soft Law
}

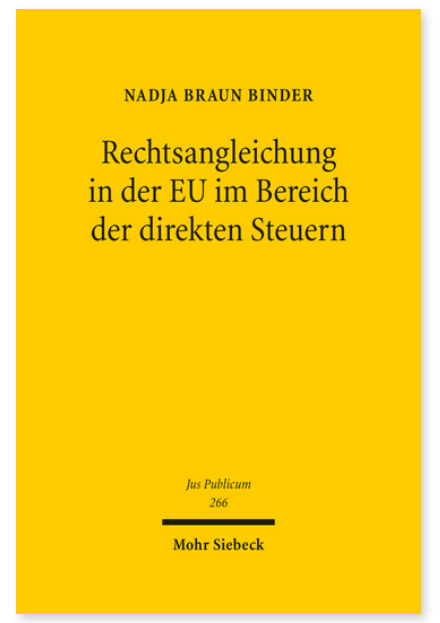

2017. XVIII, 254 Seiten. JusPubl 266

ISBN 978-3-16-155283-0

DOI 10.1628/978-3-16-155283-0

eBook PDF 99,00€

ISBN 978-3-16-155282-3

Leinen $99,00 €$
Nadja Braun Binder untersucht die Handlungsformen der Rechtsangleichung in der EU im Bereich der direkten Steuern. Zu diesem Zweck analysiert sie die primärrechtlich vorgesehenen Maßnahmen und eruiert die tatsächlich genutzten Instrumente. Dazu gehören neben den Richtlinien, den Formen der negativen Rechtsangleichung durch die Rechtsprechung des EuGH oder den Beihilfenaufsichtsverfahren auch die Maßnahmen des Soft Law. Die Autorin zeigt auf, dass die tatsächlich verwendeten Handlungsformen verschiedentlich miteinander gekoppelt sind und sich teilweise gegenseitig in ihrer Wirkung verstärken. Dies trifft in besonderer Weise für die Soft-Law-Maßnahmen und die Rechtsprechung des EuGH zu. Damit diese Korrelationen in den Blick genommen und in ihrer Tragweite erfasst werden können, ergänzt die Autorin die bislang häufig dualistisch ausgerichtete Einteilung in positive und negative Rechtsangleichung um Kategorien der legislativen, judiziellen und exekutiven Rechtsangleichung.

Nadja Braun Binder Geboren 1975; Studium der Rechtswissenschaften an den Universitäten Bern und Helsinki; 2005 Promotion; Juristin, Projektleiterin und Leiterin der Sektion Recht der Schweizer Bundeskanzlei; 2008 MBA in Public Management an der Universität Salzburg; seit 2011 Forschungsreferentin am Deutschen Forschungsinstitut für öffentliche Verwaltung (Speyer); seit 2016 dort Koordinatorin des Programmbereichs »Transformation des Staates in Zeiten der Digitalisierung«; 2017 Habilitation.

\section{Jetzt bestellen:}

https://mohrsiebeck.com/buch/rechtsangleichung-in-der-eu-im-bereich-der-direkten-steuern-9783161552830?no_cache=1 order@mohrsiebeck.com

Telefon: +49 (0)7071-923-17

Telefax: $+49(0) 7071-51104$ 